\title{
Rancang Bangun Alat Monitoring Tekanan Darah Berbasis Internet of Things (IoT)
}

Aprilia Sulista ${ }^{1}$, Nehru $^{1}$, dan Samratul Fuady ${ }^{1}$

${ }^{1}$ Program Studi Teknik Elektro, Fakultas Sains dan Teknologi, Universitas Jambi, Indonesia

Email: apriliasulista07@gmail.com, nehru@unja.ac.id, sfuady@unja.ac.id

\section{Info Artikel}

Diterima: 5 Januari 2021

Disetujui: 26 Januari 2021

Dipublikasikan: 29 Januari 2021

Alamat Korespondensi: apriliasulista07@gmail.com

Copyright (C) 2021 Jurnal Engineering

This work is licensed under the Creative Commons Attribution International License (CC BY 4.0).

\section{Abstrak}

Hipertensi menjadi salah satu permasalahan kesehatan yang serius dan menjadi penyebab kematian nomor satu di dunia setiap tahunnya. Hal ini dapat terjadi karena beberapa faktor salah satunya yaitu tidak dilakukannya pengecekan tekanan darah secara berkala, sehingga seseorang tidak mengetahui kondisi tekanan darah pada dirinya. Maka dari itu, pada penelitian ini dirancang dan dibuat sebuah Alat Montoring Tekanan Darah Berbasis Internet of Things (IoT), selain dapat mengukur tekanan darah secara digital dan pembacaan hasil pengukurannya praktis, kondisi pasien juga dapat dipantau selama 24 jam secara langsung (online) dengan melalui website yang bisa diakses di mana pun. Penelitian ini menggunakan metode riset dan pengembangan Analysis, Design, Develop, Implement, dan Evaluate (ADDIE), yang di dalamnya terdapat analisis kebutuhan Hardware dan Software yang digunakan dalam melakukan perancangan dan pembuatan alat. Hadwareyang digunakan meliputi, sensor tekanan MPX5700AP, motor pompa DC, solenoid valve, LCD, relay, Arduino Uno, NodeMCU, dan manset untuk mengukur tekanan darah. Sedangkan untuk software digunakan Arduino IDE sebagai media pembuatan program alat yang akan dirancang. Berdasarkan hasil pengujian yang telah dilakukan, diperoleh hasil uji coba prototype dari 10 sampel dengan rata-rata persentase error sistole sebesar $2,47 \%$ dan rata-rata persentase error diastole sebesar 3,385 \%. Sedangkan untuk pengujian waktu pengiriman ke website dari 10 kali percobaan dengan waktu yang berbeda diperoleh rata-rata waktu pengiriman sebesar 1,9 detik dan pada pengujian keseluruhan, sistem telah bekerja sesuai dengan yang diharapkan. Hal ini menunjukan bahwa alat yang telah dirancang dan dibuat mampu memberikan respon yang sesuai dengan apa yang telah dikonsepkan.

Kata kunci : Tekanan Darah, Sensor Tekanan MPX5700AP, Arduino Uno, Internet of Things (IoT). 


\section{Pendahuluan}

Tekanan darah adalah tekanan dari aliran darah dalam pembuluh nadi arteri (Fitriani, 2017). Tekanan darah penting karena merupakan kekuatan pendorong bagi darah agar dapat beredar ke seluruh tubuh untuk memberikan darah segar yang mengandung oksigen dan nutrisi ke organ-organ tubuh. Tekanan darah bervariasi untuk berbagai alasan, seperti usia, aktivitas fisik, dan perubahan posisi. Untuk orang dewasa, 120/80 mmHg dianggap sebagai nilai tekanan darah normal, tetapi berbeda dengan anakanak yang nilai tekanan darahnya lebih rendah daripada orang dewasa (Amirrudin, 2015). Tekanan darah paling tinggi terjadi ketika jantung berdetak/ berkontraksi memompa darah atau disebut tekanan sistolik. Sedangkan tekanan darah menurun saat jantung rileks diantara dua denyut nadi disebut tekanan diastolik. Dari perbandingan nilai tekanan darah antara tekanan darah sistolik dan tekanan darah diastolik, maka dapat diketahui bahwa tekanan darah dapat berupa tekanan darah tinggi (hipertensi), tekanan darah rendah (hipotensi), ataupun tekanan darah normal (Hidayah, 2017).

Salah satu permasalahan kesehatan yang sering menimpa negara maju dan negara berkembang adalah tekanan darah tinggi atau sering disebut hipertensi. Hipertensi sering disebut penyakit sillent killer karena penyebab aslinya tidak diketahui atau tanpa gejala sama sekali dan dapat menyebabkan berbagai penyakit komplikasi lainnya, seperti penyakit jantung, kebutaan, ginjal, dan stroke hingga kematian (Ratnadewi, 2018). Menurut data World Health Organization (WHO) tahun 2015 menunjukkan sekitar 1,13 miliar orang di dunia menyandang hipertensi, artinya 1 dari 3 orang di dunia terdiagnosis hipertensi (Andriani, 2019). Pola hidup sehat sangat diperlukan agar dapat mencegah terjadinya hipertensi (Sunarti, 2015). Selain itu, dengan melakukan pengukuran tekanan darah secara rutin dan berkala juga membantu mencegah terjadinya hipertensi. Pengukuran tekanan darah dapat dilakukan dengan 2 metode, yaitu metode langsung dan metode tidak langsung. Pengukuran dengan metode langsung dilakukan dengan cara invasive yaitu dengan memasukan alat pengukur tekanan ke sebuah jarum yang kemudian dimasukkan ke dalam arteri sedangkan pengukuran dengan metode tidak langsung atau disebut non-invasive dapat dilakukan dengan tensimeter atau sphygmomanometer dan stetoskop (Octiaraestya, 2015). Secara umum, metode non-invasive menggunakan sensor optik untuk mendeteksi dan merekam pulsa (Noche, 2017).

Seiring dengan perkembangan teknologi yang semakin pesat, maka terciptalah alat-alat baru serba otomatis dan digital yang dapat membantu para pekerja kesehatan, salah satunya yaitu alat ukur tekanan darah manusia. Penelitian terdahulu yang telah dilakukan mengenai pengembangan alat pengukur tekanan darah, di antaranya penelitian oleh (Yazid, 2011) dengan judul Pemantau Tekanan Darah Berbasis Sensor Tekanan MPX2050GP dengan mikrokontroler yang digunakan yaitu Atmega 32 dan penelitian oleh (Hendrayana, 2016) dengan judul Rancang Bangun Alat Pengukur Tekanan Darah Otomatis Menggunakan Metode Oscillometry Berbasis Raspberry PI Model B+ yang menggunakan sensor MPX53-GP sebagai pendeteksi tekanan.

Pada penelitian ini dirancang dan dibuat alat monitoring tekanan darah berbasis Internet of Things, selain dapat mengukur tekanan darah secara digital dan pembacaan hasil pengukurannya praktis, kondisi pasien juga dapat dipantau selama 24 jam secara langsung (online) melalui website ThingSpeak yang bisa diakses di mana pun, sehingga mempermudah para pekerja kesehatan untuk memantau kondisi pasien secara berkala dan langsung dapat melakukan penanganan jika terjadi masalah yang serius. Sistem berbasis IoT agar jarak tidak menjadi kendala dalam proses monitoring. Internet of Things (IoT) merupakan suatu konsep yang betujuan untuk memperluas manfaat dari konektivitas internet yang tersambung secara terus 
menerus dan digunakan untuk menghubungkan mesin, peralatan, dan benda fisik lainnya dengan sensor jaringan dan aktuator untuk memperoleh data dan mengelola kinerjanya sendiri, sehingga memungkinkan mesin untuk berkolaborasi dan bahkan bertindak berdasarkan informasi baru yang diperoleh secara independen (Arafat, 2016). Sedangkan, Thingspeak merupakan sebuah layanan internet yang menyediakan layanan untuk pengaplikasian "Internet of Things (IoT)" . Thingspeak berisi aplikasi dan Application Programming Interface (API) yang besifat open source untuk menyimpan dan mengambil data dari berbagai perangkat yang menggunakan Hypertext Transfer Protocol (HTTP) melalui internet atau Local Area Network (LAN) (Alfannizar, 2018).

\section{Perancangan}

Pada bagian ini akan dijelaskan mengenai perancangan alat monitoring tekanan darah berbasis Internet of Things (IoT).

\subsection{Perancangan Sistem}

Perancangan sistem harus memiliki konsep terlebih dahulu, agar sistem yang akan dirancang dapat tergambar dengan jelas mengenai ruang lingkupnya. Konsep perancangan ini memiliki 3 bagian utama, yaitu input, proses, dan ouput, seperti yang dapat dilihat pada Gambar 1 di bawah ini.

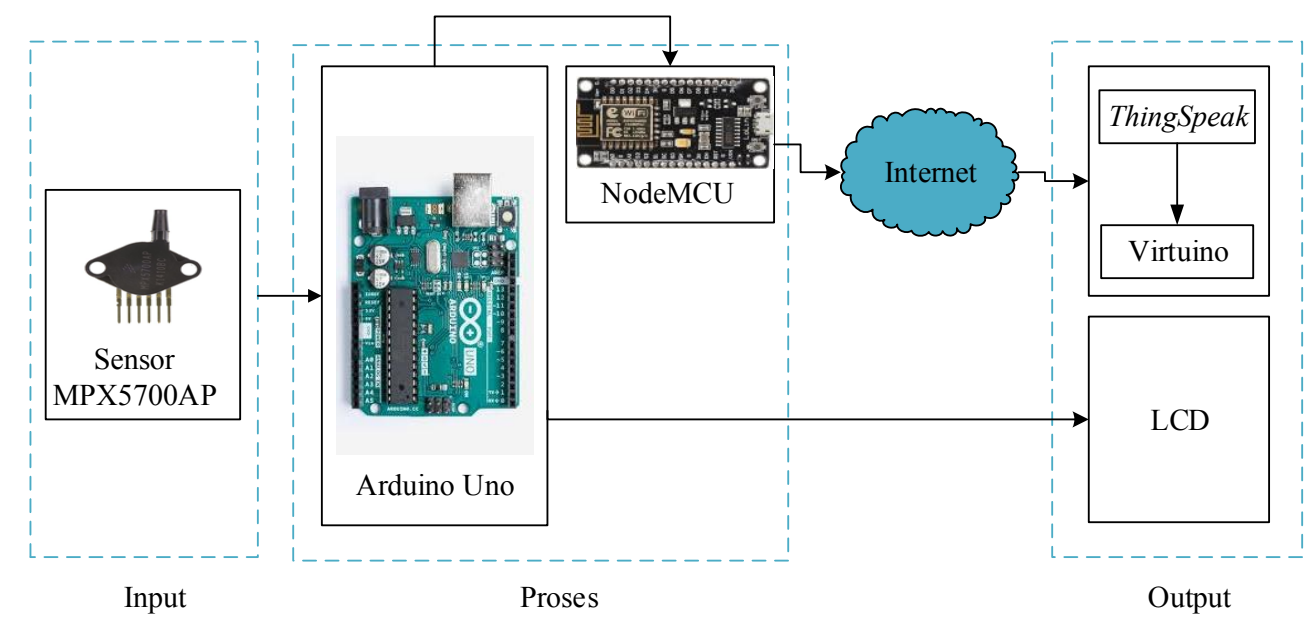

Gambar 1. Blok Diagram Perancangan Sistem

Pada Gambar 1, diketahui pada bagian input terdapat sensor tekanan MPX5700AP yang berfungsi membaca nilai tekanan pada manset yang kemudian akan dikirimkan ke mikrokontroler Arduino Uno berupa data analog. Selanjutnya pada bagian proses terdapat Arduino Uno sebagai otak dari sistem kerja alat yaitu mengolah data analog dari sensor menjadi data digital dengan Analog to Digital Converter(ADC) yang nantinya akan diolah kembali menjadi data tekanan sistole dan tekanan diastole, setelah data tekanan sistole dan diastole didapat, data tersebut akan diolah lagi pada NodeMCU untuk dikirimkan ke ThingSpeak. Kemudian pada bagian output terdapat 3 output yang ditampilkan, pertama ditampilkan pada LCD, kedua pada ThingSpeak, dan yang ketiga pada aplikasi Virtuino. Untuk pengiriman data ke ThingSpeak dan Virtuino NodeMCU harus terkoneksi dengan jaringan internet. 


\subsection{Perancangan Perangkat Keras (Hardware)}

a) Perancangan Mekanik

Perancangan mekanik pada penelitian ini yaitu perancangan penempatan posisi dari sensor yang akan digunakan. Perancangan posisi sensor didesain menggunakan aplikasi SketchUp 2017. Desain perancangan posisi sensor dapat dilihat pada Gambar 2.

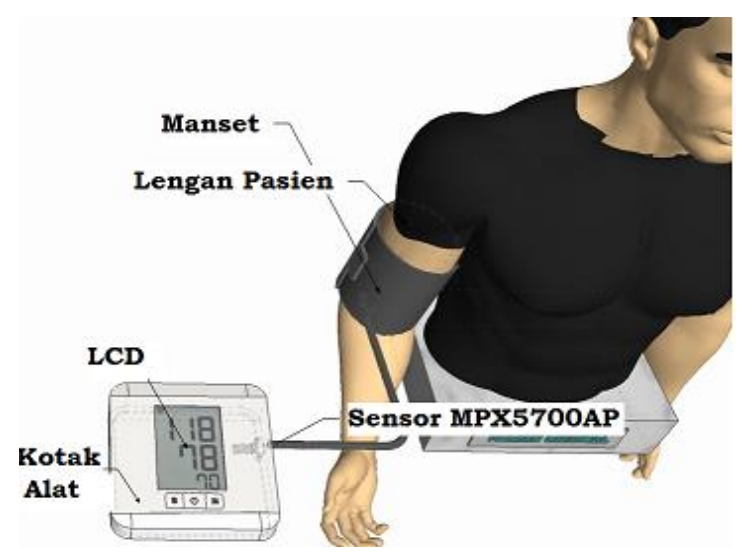

Gambar 2. Perancangan Mekanik Posisi Sensor

b) Perancangan Elektronika

Perancangan sistem elektronika ini di desain menggunakan aplikasi Fritzing 0.9.3b.64. Rangkaian elektronika merupakan rangkaian dasar dari sistem yang akan dibuat, yang terdiri dari perancangan wiring diagram dan komponen yang akan digunakan seperti sensor tekanan MPX5700AP, Arduino Uno, NodeMCU, Relay, Motor Pompa DC, Solenoid Valve, Push Button, dan LCD. Hasil desain perancangan sistem elektronika dapat dilihat pada Gambar 3.

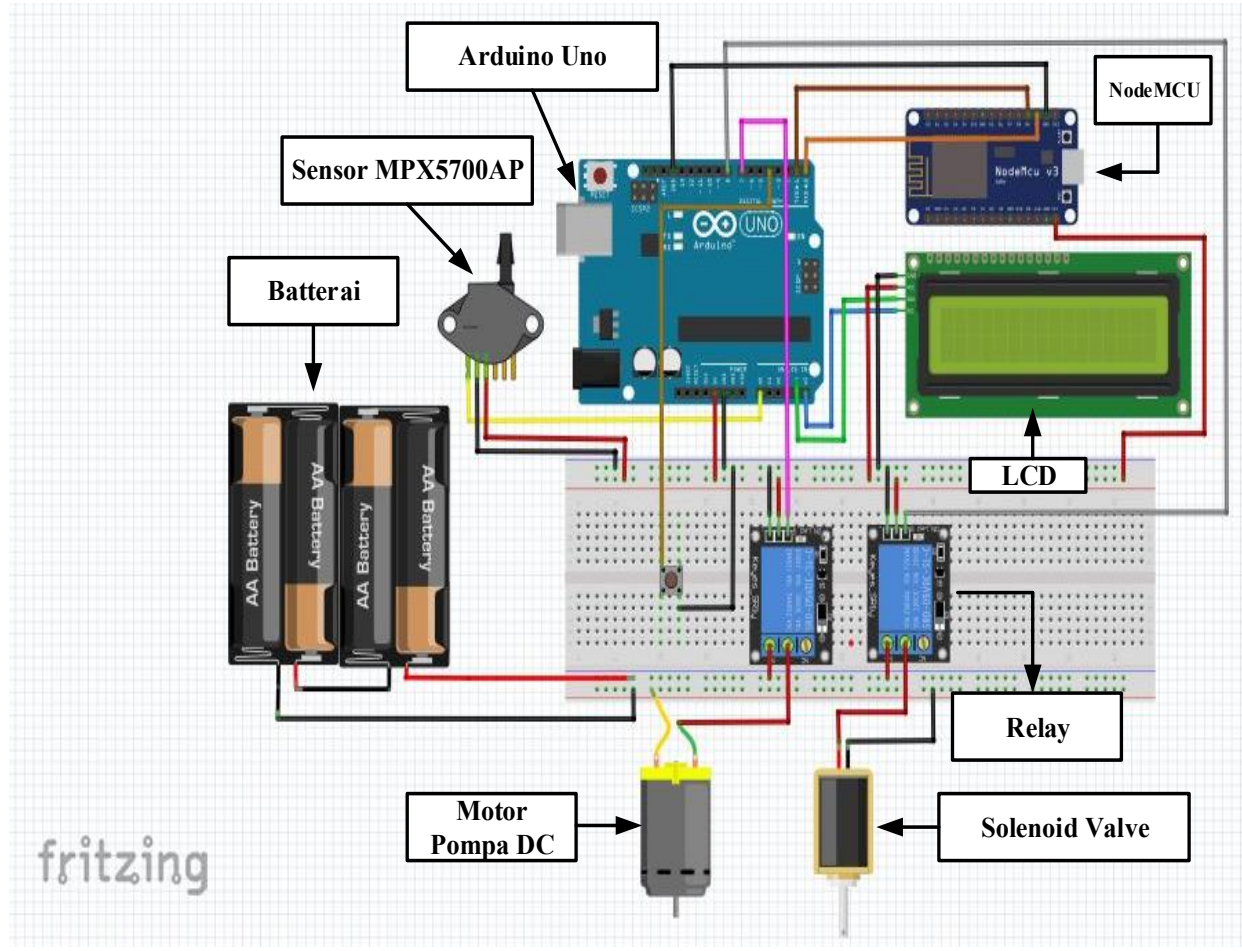

Gambar 3. Perancangan Komponen Elektronika 


\subsection{Perancangan Perangkat Lunak (Software)}

Pada tahap ini, dilakukan perancangan algoritma program untuk alat monitoring Tekanan darah berbasis IoT. Aplikasi program yang digunakan untuk menampilkan data tekanan darah dari pembacaan sensor ke Arduino Uno adalah Arduino IDE. Diagram alir dari perancangan ini dapat dilihat pada Gambar 4 dibawah ini.
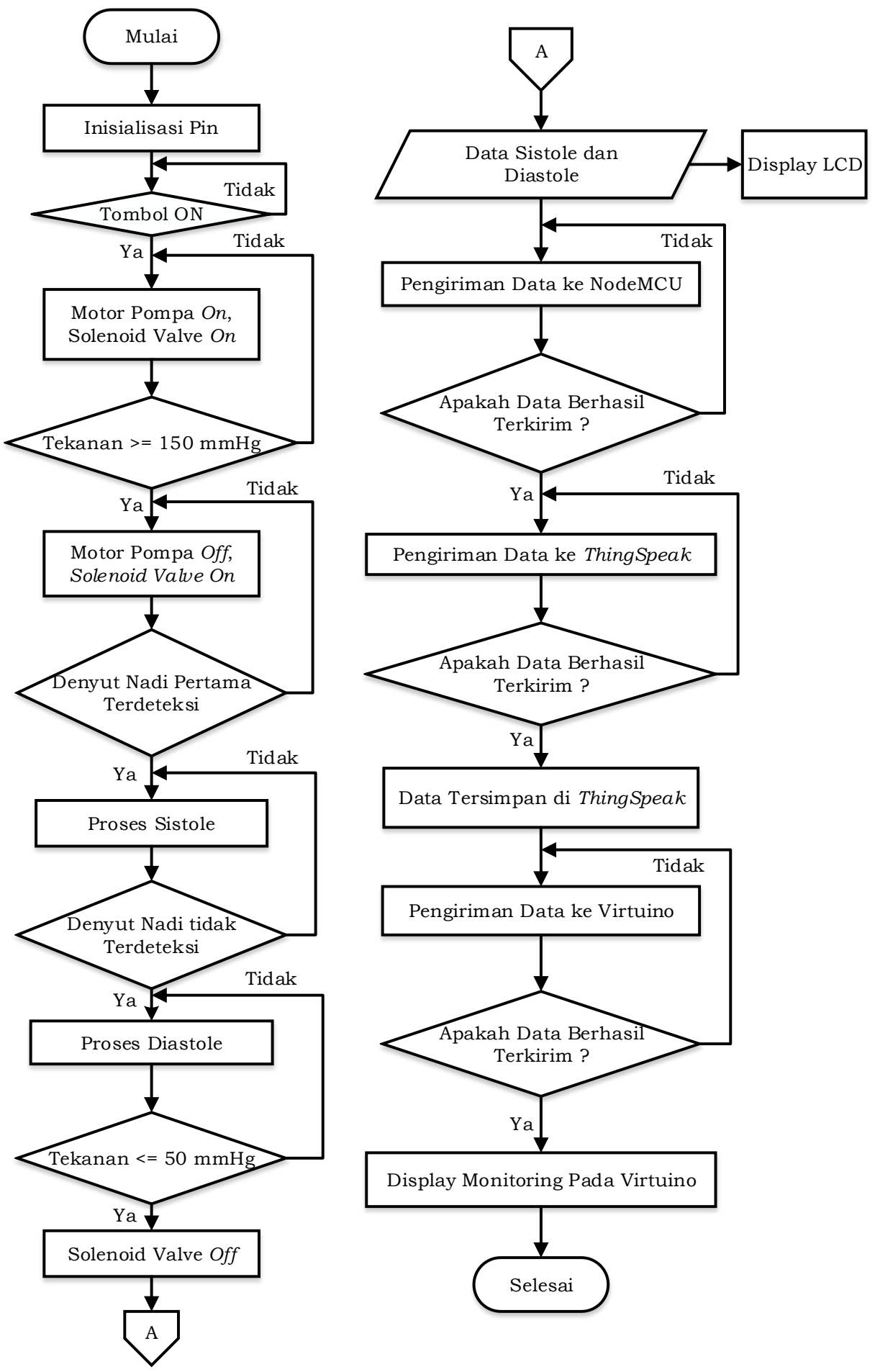

Gambar 4. Diagram Alir Perancangan Algoritma Alat Monitoring Tekanan Darah 


\section{Hasil dan Pembahasan}

\subsection{Pengujian Sensor}

Pengujian sensor dilakukan dengan menghubungkan sensor MPX5700AP dengan tensimeter aneroid, motor pompa otomatis, dan multimeter. Pada saat pengujian, sensor MPX5700AP akan dipasangkan ke tensimeter aneroid untuk melihat nilai tekanan yang diberikan, kemudian motor pompa akan memompa manset sesuai dengan tekanan yang diinginkan, setelah tercapai maka output dari sensor akan dihubungkan ke multimeter untuk dilihat besar tegangan yang terbaca.

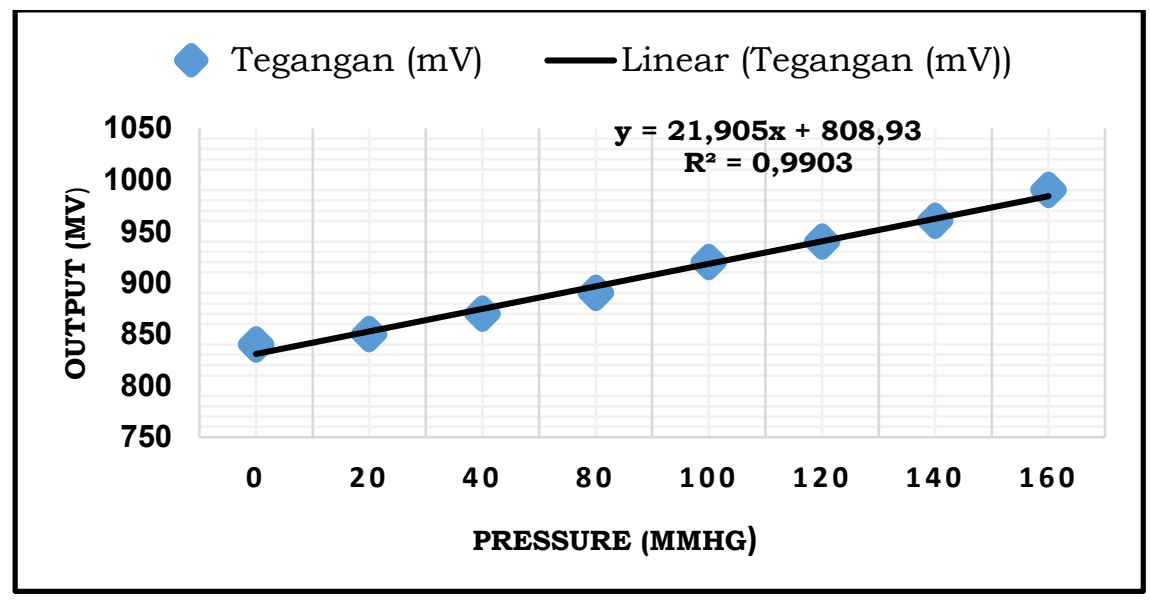

Gambar 5. Grafik hubungan antara tekanan dengan tegangan sensor MPX5700AP

Pada Gambar 5 dapat lihat bahwa sumbu x menunjukan tekanan ( $\mathrm{mmHg}$ ) yang diberikan pada sensor dan sumbu y menunjukkan output dari sensor berupa tegangan $(\mathrm{mV})$ dengan hasil pengujian output yang berupa tegangan dari sensor sebanding dan linear dengan tekanan yang diberikan. Semakin besar tekanan yang terbaca oleh sensor maka akan semakin besar pula tegangan yang dihasilkan.

\subsection{Pengujian Alat Pengukur Tekanan Darah}

Pengujian alat dilakukan dengan membandingkan nilai yang terukur pada alat yang dirancang dengan nilai yang terukur pada tensimeter digital yang ada di pasaran. Pada penelitian ini tensimeter digital Taff-Omicron digunakan sebagai alat pembanding. Berikut data hasil pengujian alat pengukur tekanan darah. Hasil pengujian alat pengukur tekanan darah, dapat dilihat pada Tabel 1.

Berdasarkan hasil pengujian alat pengukur tekanan darah yang dilakukan sebanyak 10 kali percobaan dengan 10 orang yang berbeda, seperti yang ditunjukan pada Tabel 1, diperoleh standar deviasi pengukuran tekanan darah berupa tekanan sistole dan tekanan diastole beserta error antara alat yang dirancang dengan alat yang ada di pasaran (tensimeter digital Taff-Omicron) tidak terdapat perbedaan hasil pengukuran yang signifikan artinya nilai hasil pengukuran alat yang dirancang hampir mendekati nilai hasil pengukuran alat yang ada di pasaran. 
Tabel 1. Data Hasil Pengukuran Tekanan Darah

\begin{tabular}{|c|c|c|c|c|c|c|c|}
\hline \multirow[t]{2}{*}{ Sampel } & \multirow[t]{2}{*}{$\begin{array}{l}\text { Jenis } \\
\text { Kelamin }\end{array}$} & \multicolumn{2}{|c|}{$\begin{array}{l}\text { Alat Hasil Rancangan } \\
(\mathrm{mmHg})\end{array}$} & \multicolumn{2}{|c|}{$\begin{array}{c}\text { Tensimeter Digital } \\
\text { Taff-Omicron } \\
(\mathrm{mmHg})\end{array}$} & \multicolumn{2}{|c|}{ Error (\%) } \\
\hline & & Sistole & Diastole & Sistole & Diastole & Sistole & Diastole \\
\hline 1 & $\mathrm{~L}$ & 128 & 74 & 125 & 72 & 2,4 & 2,7 \\
\hline 2 & $\mathrm{~L}$ & 139 & 74 & 139 & 77 & 0 & 3,8 \\
\hline 3 & $\mathrm{~L}$ & 123 & 69 & 120 & 75 & 2,5 & 8 \\
\hline 4 & $\mathrm{~L}$ & 123 & 74 & 123 & 72 & 0 & 2,7 \\
\hline 5 & $\mathrm{P}$ & 117 & 80 & 119 & 81 & 1,6 & 1,2 \\
\hline 6 & $\mathrm{P}$ & 112 & 85 & 114 & 80 & 0,8 & 6,25 \\
\hline 7 & $\mathrm{~L}$ & 107 & 69 & 106 & 70 & 0,9 & 1,4 \\
\hline 8 & $\mathrm{~L}$ & 117 & 80 & 122 & 80 & 4,1 & 0 \\
\hline 9 & $\mathrm{P}$ & 112 & 64 & 103 & 61 & 8 & 4,9 \\
\hline 10 & $\mathrm{~L}$ & 107 & 69 & 112 & 67 & 4,4 & 2,9 \\
\hline \multicolumn{2}{|c|}{ Rata-rata } & & & & & 2,47 & 3,385 \\
\hline \multicolumn{2}{|c|}{ Standar Deviasi } & 10,024 & 6,390 & 10,306 & 6,416 & 2,476 & 2,434 \\
\hline
\end{tabular}

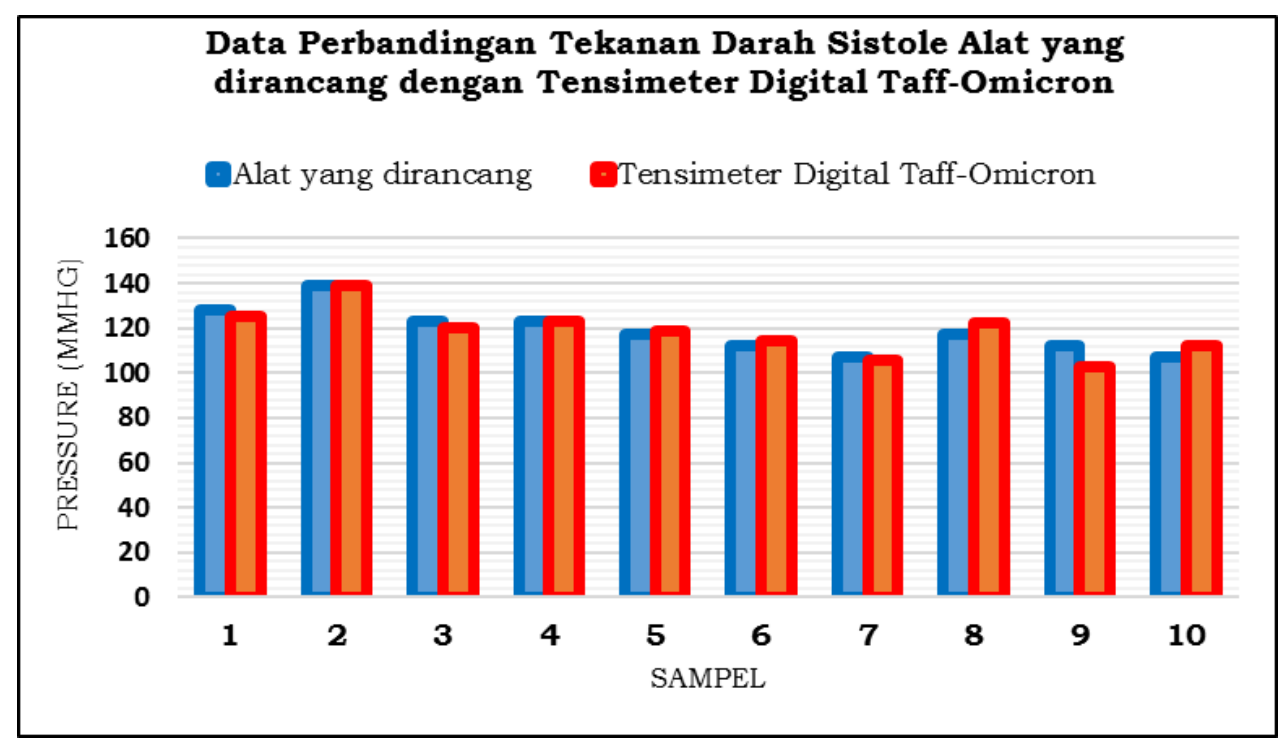

Gambar 6. Grafik Perbandingan Nilai Tekanan Darah Sistole Alat yang dirancang dengan Tensimeter Digital Taff-Omicron 


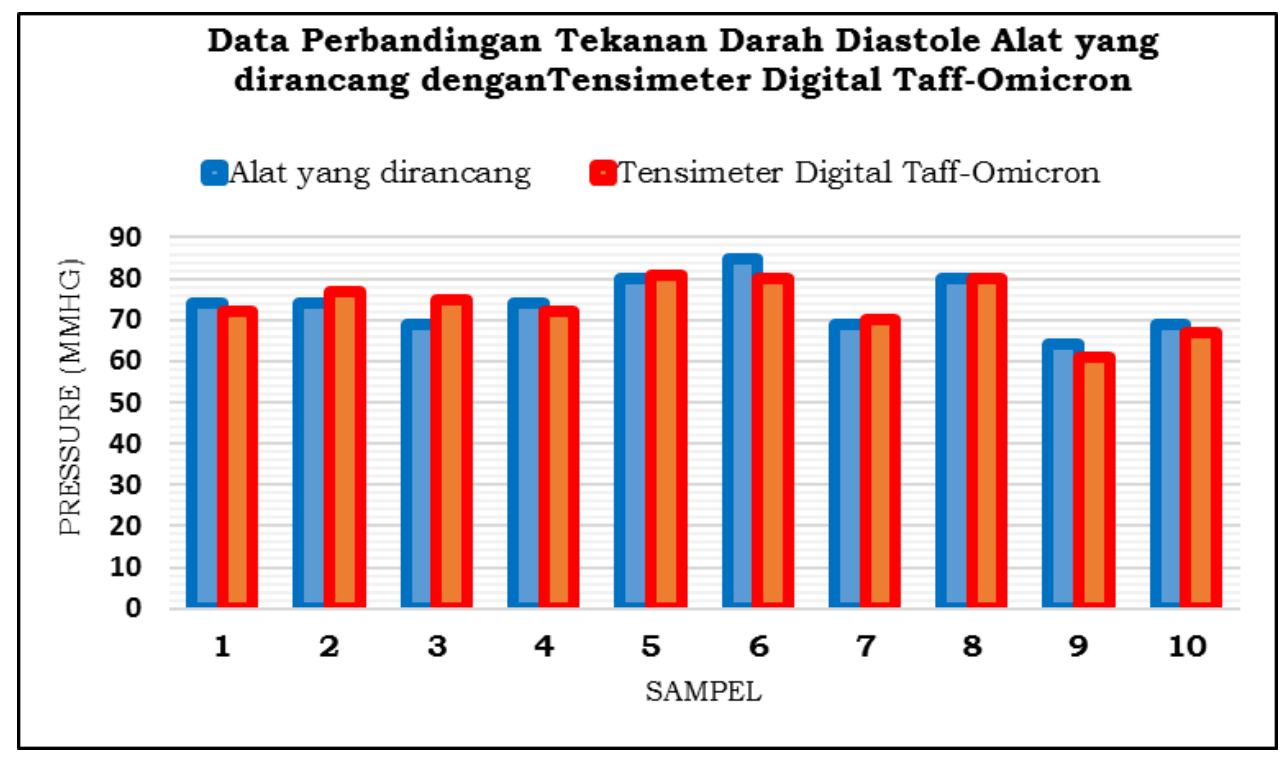

Gambar 7. Grafik Perbandingan Nilai Tekanan Darah Diastole Alat yang dirancang dengan Tensimeter Digital Taff-Omicron

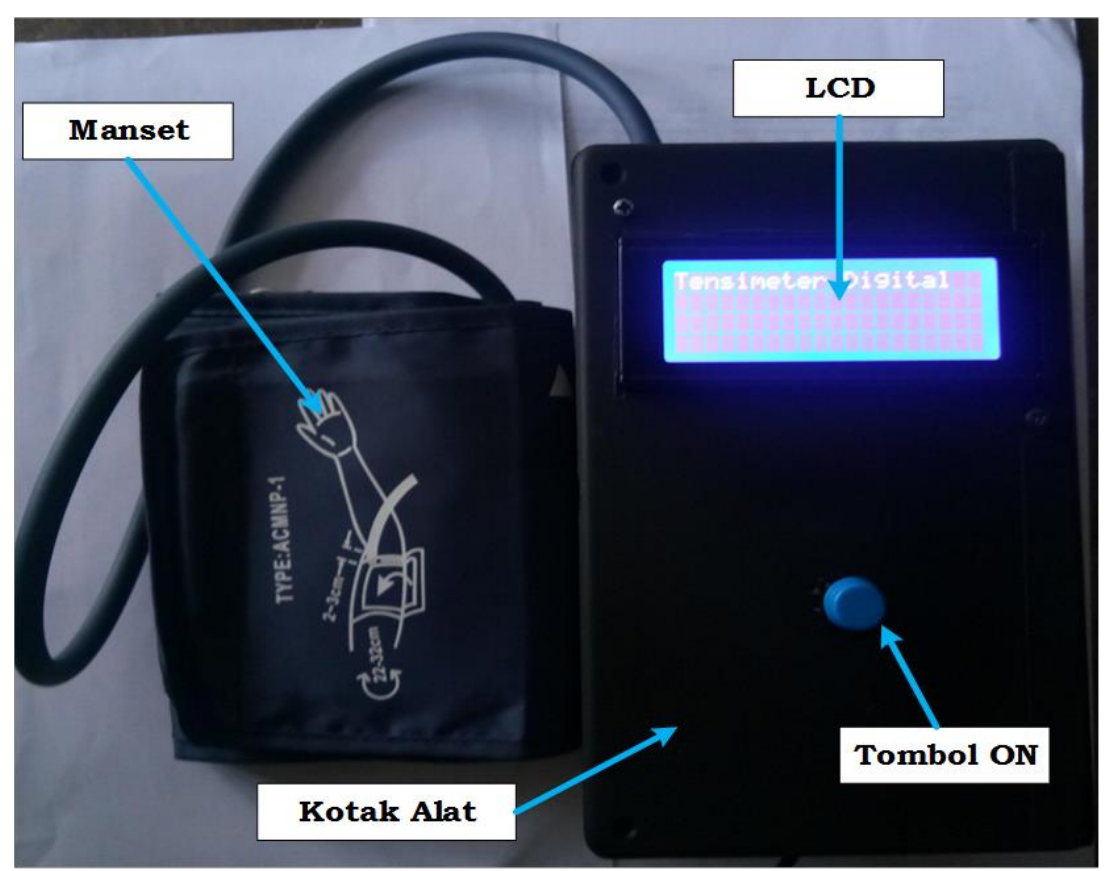

Gambar 8. Bentuk fisik hasil perancangan Alat Monitoring Tekanan Darah

\subsection{Pengujian Waktu Pengiriman Data ke ThingSpeak}

Pengujian dilakukan ini sebanyak 10 kali percobaan dengan waktu yang berbeda, hal ini ditujukan untuk mengetahui perbandingan atau selisih waktu pengiriman data dari alat ke website ThingSpeak. Data hasil pengujian dapat dilihat pada Tabel 2. 
Tabel 2. Hasil Perbandingan Waktu yang Terbaca di LCD dengan waktu yang Terkirim ke ThingSpeak

\begin{tabular}{cccc}
\hline Percobaan ke- & $\begin{array}{c}\text { Waktu Terbaca di } \\
\text { LCD }\end{array}$ & $\begin{array}{c}\text { Waktu Terkirim ke- } \\
\text { ThingSpeak }\end{array}$ & $\begin{array}{c}\text { Selisih Waktu } \\
\text { (Detik) }\end{array}$ \\
\hline 1 & $10: 24: 31$ WIB & $10: 24: 33$ WIB & 2 \\
2 & $11: 03: 03$ WIB & $11: 03: 03$ WIB & 0 \\
3 & $11: 54: 00$ WIB & $11: 54: 04$ WIB & 4 \\
4 & $12: 30: 48$ WIB & $12: 30: 48$ WIB & 0 \\
5 & $13: 06: 19$ WIB & $13: 06: 22$ WIB & 3 \\
6 & $13: 39: 23$ WIB & $13: 39: 23$ WIB & 0 \\
7 & $14: 10: 54$ WIB & $14: 10: 56$ WIB & 2 \\
8 & $14: 47: 20$ WIB & $14: 47: 24$ WIB & 4 \\
9 & $15: 18: 21$ WIB & $15: 18: 24$ WIB & 3 \\
10 & $15: 43: 32$ WIB & $15: 43: 33$ WIB & 1 \\
\hline \multicolumn{5}{c}{ Jumlah } & 19 \\
\hline
\end{tabular}

\subsection{Pengujian Keseluruhan}

Pengujian ini dilakukan untuk menguji fungsional dari hardware terhadap pengguna, yang akan dilihat respon pada saat sensor mebaca data tekanan lalu dikirim ke Arduino Uno, Arduino mengolah data tekanan menjadi tekanan sistole dan diastole, kemudian Arduino mengirim data ke NodeMCU, NodeMCU mengirim data ke ThingSpeak dan ThingSpeak mengirim data ke Apikasi Virtuino.

a) Pengiriman Data Sensor ke Mikrokontroler Arduino Uno

Tabel 3. Pengujian Pengiriman data sensor ke Mikrokontroler Arduino Uno

\begin{tabular}{ccc}
\hline Skenario Pengujian & Hasil yang diharapkan & Kesimpulan \\
\hline Sensor membaca data tekanan & Data tekanan dari sensor terkirim & Valid \\
dari manset & ke mikrokontroler Arduino dan & \\
& ditampilkan di serial monitor & \\
( Lihat Gambar 9 (a)) & $($ Lihat Gambar 9 (b)) & \\
\hline
\end{tabular}




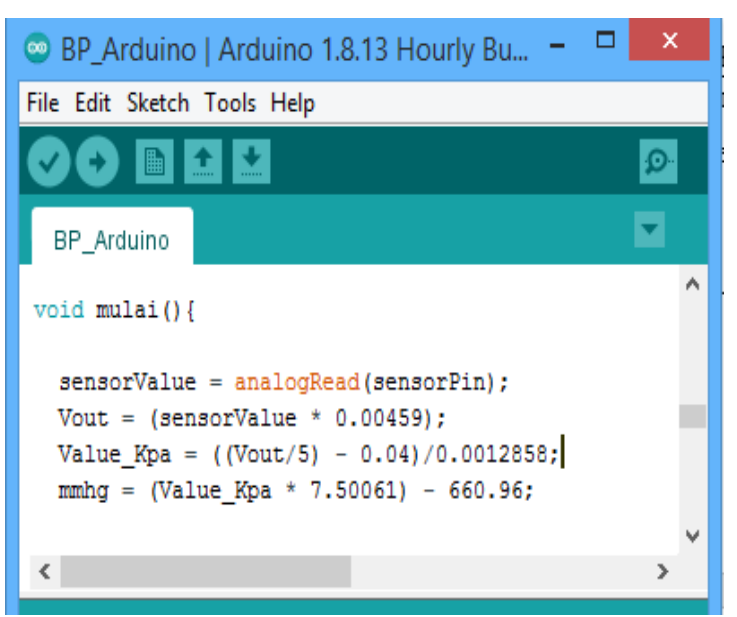

(a)

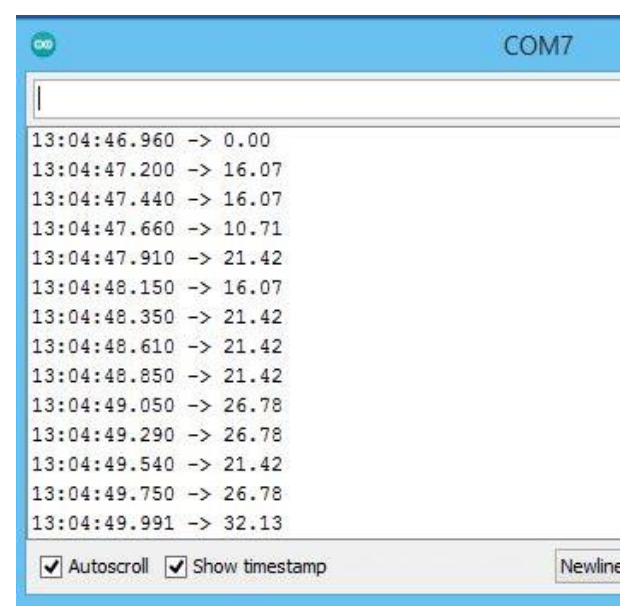

(b)

Gambar 9. (a) Program Pembacaan Data Sensor (b) Hasil Pengujian Pegiriman data Sensor ke Mikrokontroler Arduino

b) Arduino mengolah data tekanan menjadi tekanan Sistole dan Diastole

Tabel 4. Pengujian Program pengolahan data tekanan menjadi tekanan Sistole dan Diastole pada Arduino

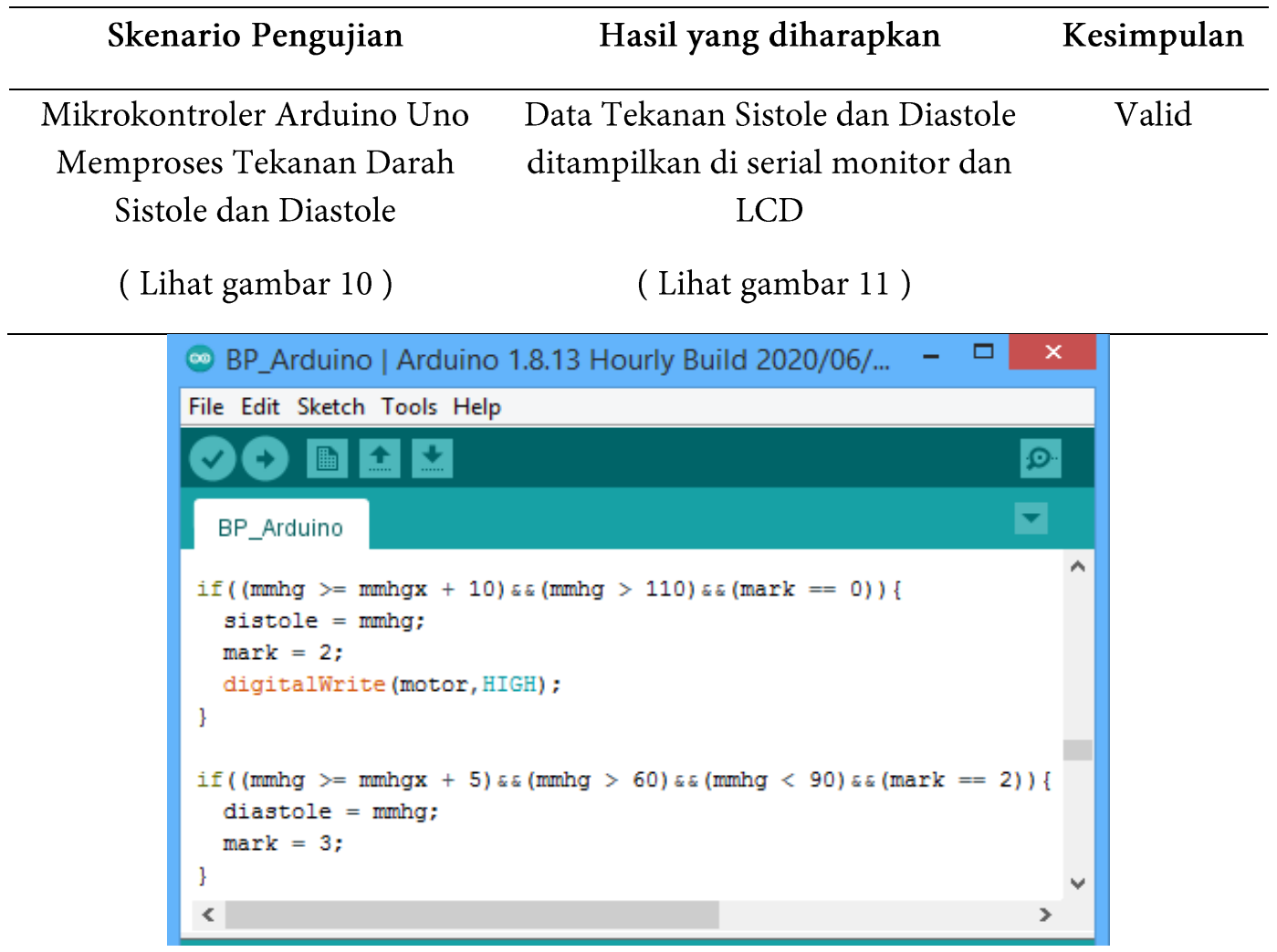

Gambar 10. Program Pengolahan Data Tekanan menjadi Tekanan Sistole dan Diastole 


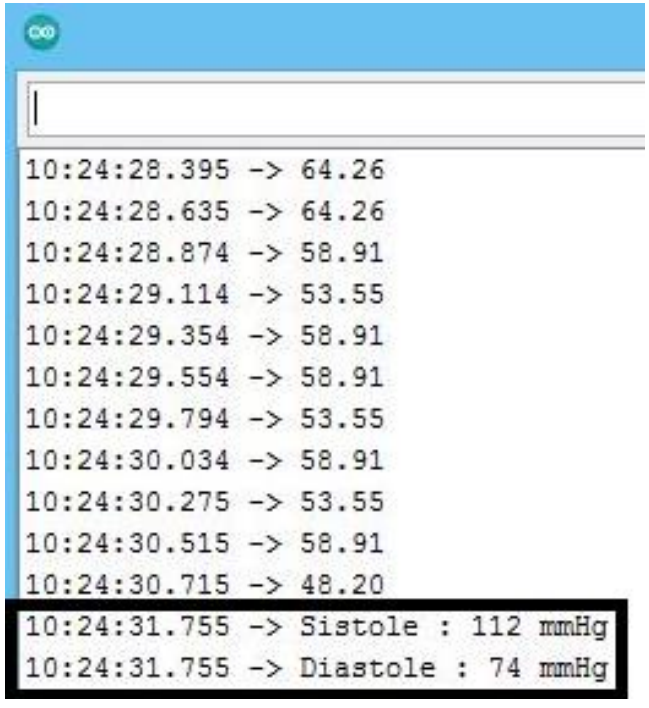

(a)

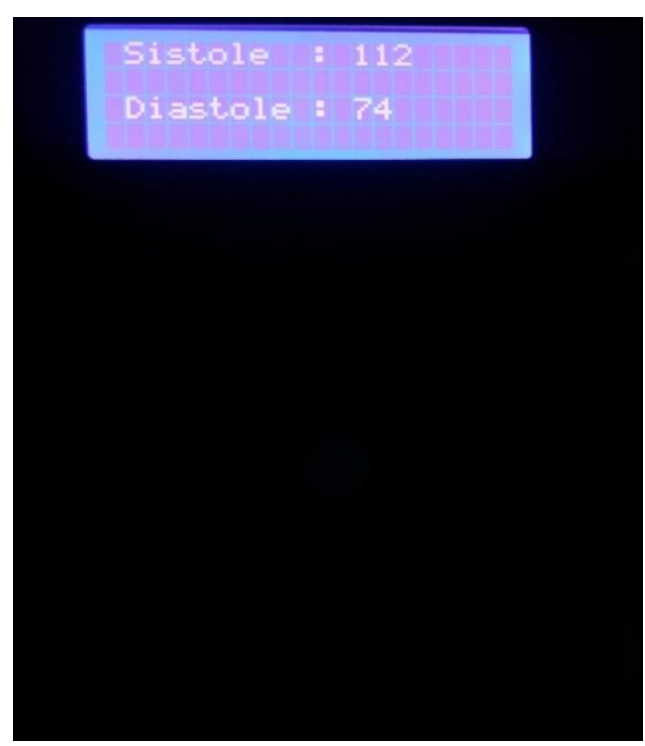

(b)

Gambar 11. (a) Tampilan pada Serial Monitor (b) Tampilan Pada LCD

c) Arduino mengirim data Sistole dan Diastole ke NodeMCU

Tabel 5. Pengujian pengiriman data Sistole dan Diastole ke NodeMCU

\begin{tabular}{ccc}
\hline Skenario Pengujian & Hasil yang diharapkan & Kesimpulan \\
\hline Arduino mengirim data Sistole & NodeMCU menerima data Sistole & Valid \\
dan Diastole ke NodeMCU & dan Diastole & \\
$($ Lihat gambar 12) & $($ Lihat gambar 13) & \\
\hline
\end{tabular}

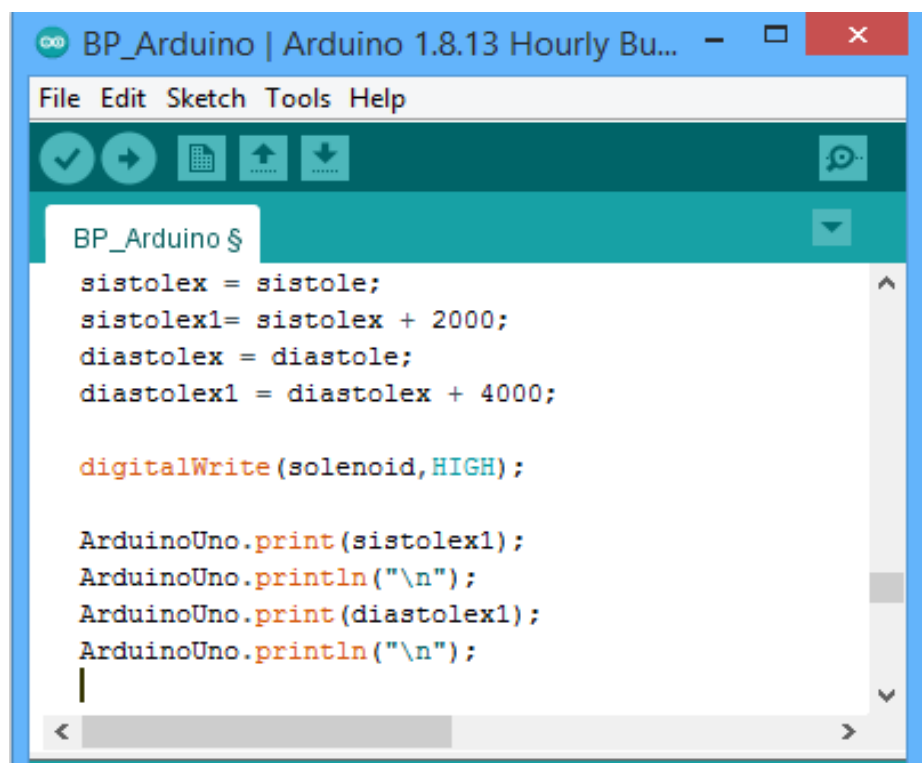

Gambar 12. Program Pengiriman Data ke NodeMCU 


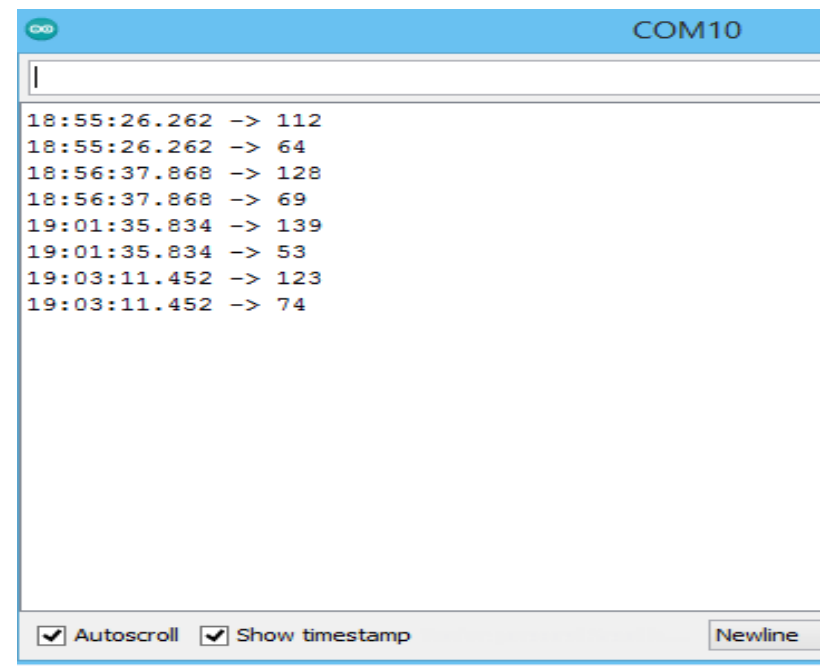

Gambar 13. Tampilan Data yang diterima NodeMCU dari Arduino pada Serial Monitor

d) NodeMCU mengirim data Sistole dan Diastole ke ThingSpeak

Tabel 6. Pengujian Pengiriman data Sistole dan Diastole ke ThingSpeak menggunakan NodeMCU

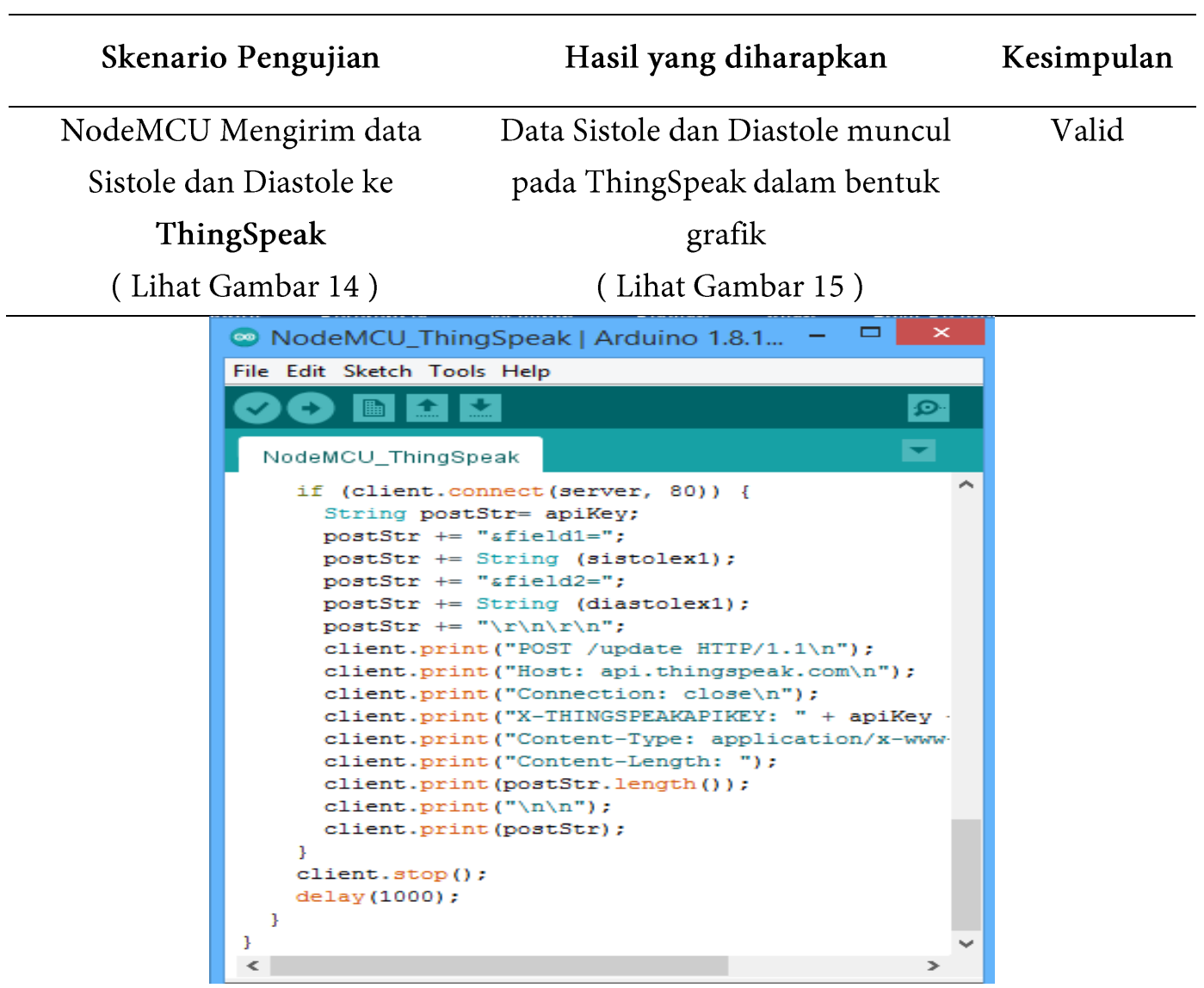

Gambar 14. Program pengiriman data ke ThingSpeak 


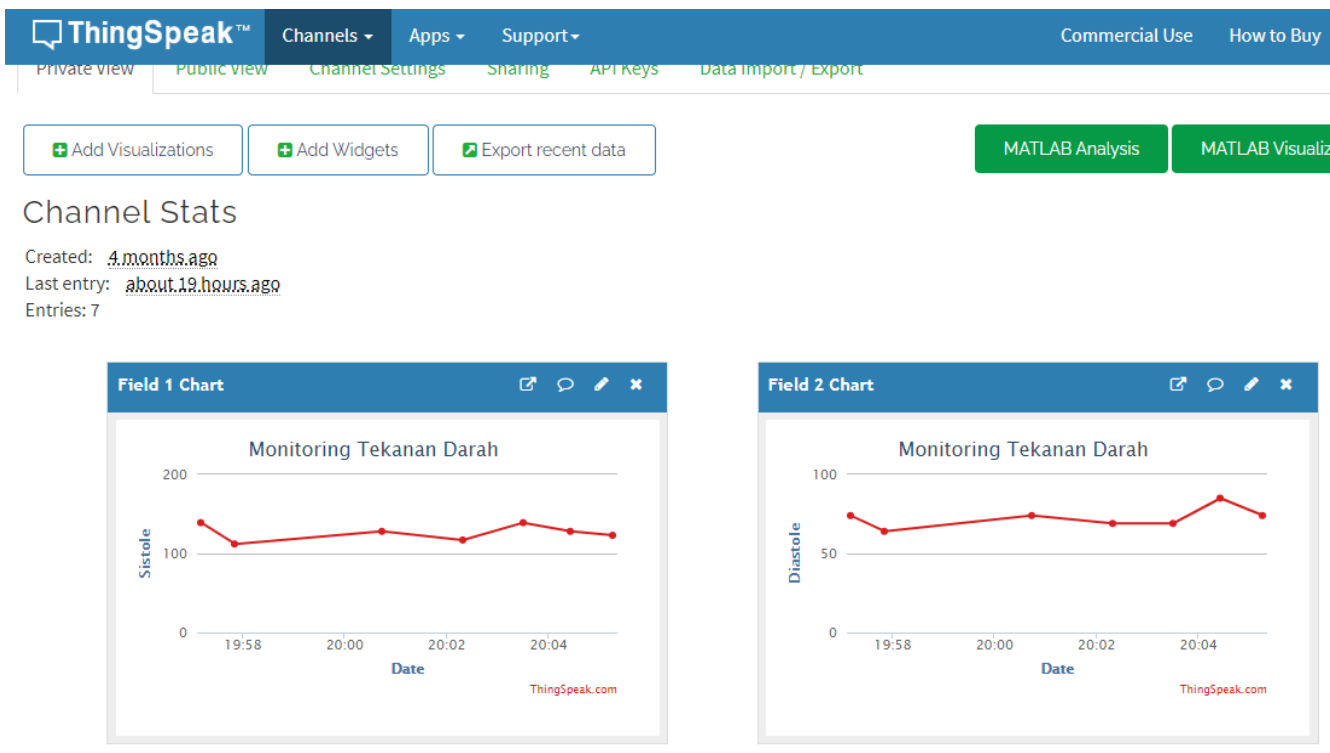

Gambar 15. Tampilan Data Sistole dan Diastole pada ThingSpeak

e) ThingSpeak Mengirim Data Sistole dan Diastole ke Aplikasi Virtuino

Tabel 7. Pengujian Pengiriman data Sistole dan Diastole ke Virtuino

\begin{tabular}{ccc}
\hline Skenario Pengujian & Hasil yang diharapkan & Kesimpulan \\
\hline Virtuino Mengambil data & Data Sistole dan Diastole mucul di & Valid \\
Sistole dan Diastole dari & Aplikasi Virtuino & \\
ThingSpeak & ( Lihat gambar 16) & \\
\hline
\end{tabular}

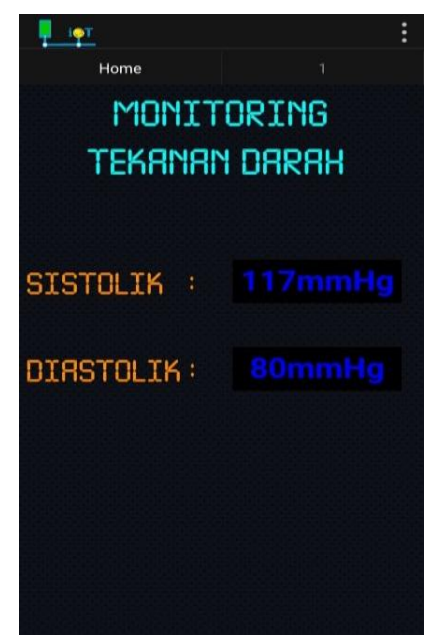

(a)

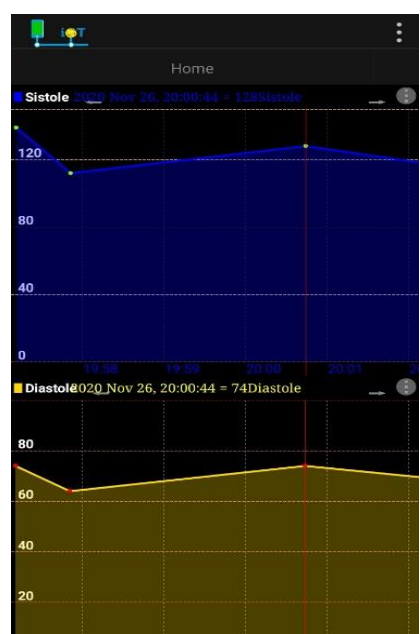

(b)

Gambar 16. Tampilan Data Sistole dan Diastole pada Virtuino

Berdasarkan hasil pengujian, diketahui bahwa alat yang telah dirancang dan dibuat mampu memberikan respon yang sesuai dengan apa yang telah dikonsepkan. 


\section{Kesimpulan}

Berdasarkan pengujian dari penelitian yang dilakukan, maka dapat disimpulkan sebagai berikut:

1. Alat Monitoring Tekanan Darah Berbasis IoT yang telah dibuat dapat bekerja sesuai dengan yang diinginkan dan dapat dimonitoring melalui website ThingSpeak maupun Apikasi Virtuino pada SmartPhone Android menggunakan jaringan Internet.

2. Rata-rata error dari hasil pengujian alat pengukur tekanan darah pada 10 (sepuluh) sampel berbeda adalah tekanan darah sistole sebesar $3 \mathrm{mmHg}$ atau 2,47\% dan tekanan darah diastole sebesar 2,5 $\mathrm{mmHg}$ atau $3,385 \%$, hal ini menunjukan bahwa alat yang dirancang layak untuk digunakan karena mengacu kepada standar kesalahan pengukuran yang diperbolehkan yaitu sebesar $3 \mathrm{mmHg}$.

3. Rata-rata selisih waktu dari hasil pengujian pengiriman data ke ThingSpeak sebesar 1,9 detik.

\section{Daftar Pustaka}

[1] N. Fitriani dan N. Nilamsari, "Faktor-faktor yang berhubungan dengan Tekanan Darah Pada Pekerja Shift dan Pekerja Non-Shift di PT. X Gresik," Journal of Industrial Hygiene and Occupational Health, Vol. 2, No. 1, pp. 58-59, 2017.

[2] M. A. Amirrudin, "Analisa Hasil Pengukuran Tekanan Darah Antara Posisi Duduk dan Posisi Berdiri Pada Mahasiswa Semester VII (Tujuh) TA. 2014/2015 Fakultas Kedokteran Universitas Sam Ratulangi," Jurnal e-Biomedik (Ebm), Volume 3, Nomor 1, pp. 126-127, 2015.

[3] S. N. Hidayah, "Hubungan Obesitas Dengan Tekanan Darah di RT 05 Desa Kalisapu Kecamatan Slawi Kabupaten Tegal," Jurnal Sirklus Vol. 6 No. 2, pp. 223-2234, 2017.

[4] Ratnadewi, M. F. Ramdhani, N. Kurniasih, L. D. Putri, Parwito, D. Abdullah, T. Listyorini, M. I. Bakhtiar, R. F. Nanuru dan R. Rahim, "Automatic Blood Pressure Detector Using Arduino to Measure Blood Pressure in Indonesian People Age 19-27 Years Old," International Journal of Engineering \& Technology, 7(2.5), pp. 115-118, 2018.

[5] Andriani dan M. Sari, "Efektifitas Pemberian Jus Belimbing Manis dan Mentimun Terhadap Tekanan Darah Penderita Hipertensi,” Jurnal Kesehatan, ISSN 2085-7098, pp. 150-155, 2019.

[6] Sunarti, I. Sunarno dan Alvino, "Upaya Penderita Hipertensi Untuk Mempertahankan Pola Hidup Sehat (Hypertension Patients Efforts to Maintain Healthy Lifestyles)," Jurnal Ners dan Kebidanan, Volume 2, Nomor 2, Agustus 2015, pp. 122-129, 2015.

[7] Octiaraestya, "Metode Palpasi dan Auskultasi," SCRIBD, 14 May 2015. [Online]. Available: https://id.scribd.com. [Diakses 29 January 2020].

[8] K. J. B. Noche, J. F. Villaverde dan J. Lazaro Jr. , "Portable Non-invasive Blood Pressure Measurement," IEEE, pp. 1-2, 2017.

[9] N. Yazid dan A. Harjoko, "Pemantau Tekanan Darah Digital Berbasis Sensor Tekanan MPX2050GP," IJEIS, Vol. 1 No.1, pp. 35-36, 2011.

[10] Y. H. Hendrayana, M. A. Riyadi dan Darjat, "Rancang Bangun Alat Pengukur Tekanan Darah Otomatis Menggunakan Metode Oscillometry Bebasis Raspberry PI Model B+," TRANSMISI, 18, (1), JANUARI 2016, e-issn 2407 - 6422, 39, 2016.

[11] M. Arafat, "Sistem Pengaman Pintu Rumah Berbasis Internet of Things (IoT) Dengan ESP8266," Jurnal Ilmiah Fakultas Teknik, pp. 262-268, 2016.

[12] I. Alfannizar dan Y. Rahayu, "Perancangan dan Pembuatan Alat Home Electricity Based Home Appliance Controller Berbasis Internet of Things," Jom FTTEKNIK Volume 5 No. 1, pp. 2-3, 2018. 